ISSN 1823-626X

Journal of Fundamental Sciences

available online at http://jfs.ibnusina.utm.my

\title{
Role of oxidant in surface modification of carbon nanotubes for tyrosinase immobilization
}

\author{
Zaiton Abdul Majid ${ }^{1 *}$, Nur Anis Mohammad Sabri ${ }^{1}$, Nor Aziah Buang ${ }^{1}$, Shafinaz Shahir ${ }^{2}$ \\ ${ }^{1}$ Department of Chemistry, Faculty of Science, Universiti Teknologi Malaysia, 81310 UTM Skudai, Johor, Malaysia \\ ${ }^{2}$ Department of Biological Sciences, Faculty of Bioscience and Bioengineering, Universiti Teknologi Malaysia, 81310 UTM Skudai, Johor, Malaysia \\ Received 20 March 2010, Revised 9 April 2010, Accepted 21 June 2010, Available online 29 June 2010
}

\begin{abstract}
Studies on the development of interface between biological molecules and novel nanomaterials have attracted research worldwide. Carbon nanotubes (CNTs) have become an important matrix for the fabrication of biomaterials due to its unique properties. Surface properties of the CNTs and the medium of immobilization are critical in the immobilization of biological molecules such as enzymes. In this study surface modification of multi-walled carbon nanotubes (MWCNTs) for carboxylic moieties attachment was accomplished by acid treatment and reaction with potassium permanganate. The effect of these two oxidants on the surface modification of MWCNTs for the purpose Tyrosinase immobilization was studied. Commercial MWCNTs were treated with either concentrated sulfuric acid and nitric acid mixture with ratio 3:1 or with $0.1 \mathrm{M}$ potassium permanganate via reflux, stirring and ultrasonication. The resulting surface modified MWCNTs were characterized with FT-IR spectrophotometer, FESEM, and TGA analyzer. The immobilized Tyrosinase was tested for leaching assay. The FTIR spectra of functionalized MWCNTs showed a significant peak in the range of $1700 \mathrm{~cm}$ ${ }^{1}$ to $1729 \mathrm{~cm}^{-1}$ indicating the presence of carboxyl double bond, which confirmed the successful functionalization of MWCNTs by chemical oxidation. The carboxylic peak of MWCNTs treated with $\mathrm{KMnO}_{4^{-}}$showed higher intensity as compared to acid-treated MWCNTs. The acid-treated MWCNTs displayed a sparkling crystalline-like particles while the $\mathrm{KMnO}_{4}$-modified MWCNTs consists of smooth powdery particles. Both treated MWCNTs also showed good dispersion in aqueous solution with different amount of acidic and basic site present.
\end{abstract}

| Carbon nanotubes| Oxidation | Enzyme immobilization |

( 2010 Ibnu Sina Institute. All rights reserved. http://dx.doi.org/10.11113/mjfas.v6n1.176

\section{INTRODUCTION}

The outstanding properties of carbon nanotubes (CNTs) have attracted researchers since the nanotubes were significantly introduced in 1991 [1]. The expected applications of the nanotubes include various field such as nanoelectronic devices, probe for scanning probe microscopy, sensors, and drug delivery [2-5]. Their applications and properties are dependent on the chemical functionalization as indicated by initial studies [6]. The presence of defects sites on CNTs can be conveniently used for chemical functionalization especially by oxidation process. The defect sites are relatively reactive with various chemical structures such as the Stone-Wales defect, pentagon-heptagon pair defect, and also structural defect [6]. These defects sites along with end caps are easier to oxidize as compared to the wall of $\mathrm{sp}^{2}$ bonded carbon. These sites are converted to oxygenated groups of carboxylic acid (R-COOH) or attached with hydroxyl group $(-\mathrm{OH})$ after chemical oxidation process, which can be used for further functionalization.

Corresponding author at: Department of Chemistry, Faculty of Science

Universiti Teknologi Malaysia, 81310 UTM Skudai, Johor, Malaysia

E-mail addresses: zaiton@kimia.fs.utm.my (Zaiton Abdul Majid)
Initial studies on functionalization of multi-walled carbon nanotubes (MWCNTs) are less reported as compared to single-walled carbon nanotubes (SWCNTs) due to the fact that functionalization of MWCNTs requires harsher condition and difficult to accomplish. However, properties of MWCNTs are relatively unaffected during functionalization because of their multi-layered structure whilst the conductive properties of SWCNTs decreased [710]. This study focused on functionalization of MWCNTs via two oxidants with different oxidation ability and also techniques used for oxidation process. In this study, three techniques are used for oxidation which are sonication, reflux, and also stirring. Some studies mix two or three techniques together for oxidation purpose because each technique have different effect in oxidation reaction as studied in this research. The resulting functionalized carbon nanotubes (FCNTs) are applicable for various applications and this study focused on immobilization of Tyrosinase onto the FCNTs.

Tyrosinase is a type of monophenol monooxygenase (EC 1.14.18.1) enzyme that catalyses the oxidation of phenols and is essential for melanization. It is found in abundance in animals and plant tissues which produces melanin and other pigments responsible for pigmentation in 
animal skin hair and air-exposed peeled fruits. Tyrosinase has been used extensively in applications of phenol biosensors, phenol and amine degradation, xenobiotic compound removal, catechol oxidation, and phenolic compounds polymerization. Its application in biosensors contributes significantly in bioremediation, wastewater treatment, and wine stabilization. Immobilization of enzyme on support had been reported for application in biomedical field. Enzymes particularly tyrosinase, urease, and glucosidase have attracted attention because of their possible application in diagnostic disease [11-13]. Thus, immobilization of enzymes on support without damaging both enzyme and support will help to fabricate device for the purpose of biosensing or diagnostic tests [14]. In this study, the Tyrosinase will be immobilized onto the FCNTs with a hypothesis. The amount of functional moieties present and dispersion stability affect the immobilization of Tyrosinase with the expectation of highest immobilization occuring on FCNTs with higher amount functional groups. The study will focus on the role of oxidant in the surface modification of MWCNTs for the purpose of Tyrosinase immobilization.

\section{EXPERIMENTAL}

\subsection{Materials}

The MWCNTs were purchased from Sun Nano, China with $>90 \%$ purity, 10-25 nm diameter, and 1-20 $\mu \mathrm{m}$ length. These nanotubes were used as received, followed by treatment with diluted nitric acid to remove the remaining impurities by refluxing for an hour at $70^{\circ} \mathrm{C}$. Other reagents such as nitric acid $\mathrm{HNO}_{3}$, sulfuric acid $\mathrm{H}_{2} \mathrm{SO}_{4}$ and potassium permanganate $\mathrm{KMnO}_{4}$ were purchased from Sigma-Aldrich and JT Baker and of analytical grade. Commercialized tyrosinase (E.C.1.14.18.1) isolated and purified from mushrooms were purchased from Sigma Aldrich with an enzyme activity of 3130 units/mg. The purchased tyrosinase was used without further purification.

\section{$2.2 \quad$ Methods}

\subsubsection{Functionalization of MWCNTs}

Purified sample of nanotubes (20 mg) was treated with either $50 \mathrm{~mL}$ of concentrated $\mathrm{H}_{2} \mathrm{SO}_{4}(98 \%) / \mathrm{HNO}_{3}$ (63\%) or $50 \mathrm{~mL} 0.1 \mathrm{M} \mathrm{KMnO}_{4}$ by sonication, reflux, and stirring. Two samples were sonicated in water bath for 6 hours, another two samples were refluxed for 4 hours at a constant temperature of $80^{\circ} \mathrm{C}$, while two more samples were stirred overnight. These are the typical techniques for chemical oxidation of CNTs as indicated by previous studies with only slight modification to avoid structural damage on the CNTs [16]. The samples were then collected by filtering with $0.2 \mu \mathrm{m}$ Nylon filter membrane, rinsed with distilled water until neutral $\mathrm{pH}$. The functionalized MWCNTs (FCNTs) were then dispersed in water to determine their suspension stability. For the dispersion test,
$0.05 \mathrm{mg}$ of six FCNTs samples was dispersed in $3 \mathrm{~mL}$ of the solvent and sonicated for 15 minutes and left to settle. Samples were observed for aggregation at regular intervals, where stable suspension will not aggregate visibly after 24 h. In addition to the dispersion test, FCNTs samples were analyzed by back titration method to determine both acidic and basic sites quantitatively. The titration method was adapted with slight modification; briefly samples were heated at $100^{\circ} \mathrm{C}$ to remove moisture [17]. The sample was then added into $0.01 \mathrm{~N} \mathrm{NaOH}$ and stirred for 48 hours and centrifuged for 15 minutes before titrating with $0.01 \mathrm{~N} \mathrm{HCl}$ using a $\mathrm{pH}$ indicator to monitor the $\mathrm{pH}$ change.

\subsubsection{Enzyme immobilization}

The immobilized tyrosinase was prepared on FCNTs as an enzyme immobilization carrier. In this work, the tyrosinase immobilization was done by physical adsorption method. Enzyme solution with concentration of approximately $0.1 \mathrm{mg} / \mathrm{mL}$ was prepared using phosphate buffer $0.1 \mathrm{mM}, \mathrm{pH}$ 7.0. The samples of FCNTs and MWCNTs were immersed into the tyrosinase solution. The mixture was incubated overnight at $4^{\circ} \mathrm{C}$. The leaching study was done on the samples for a period of time to calculate the amount of enzyme immobilized.

\subsection{Characterization}

\subsubsection{Fourier-Transform Infra-Red spectroscopy}

FT-IR spectra were recorded in transmission mode in the spectral range of $4000-400 \mathrm{~cm}^{-1}$ using potassium bromide $(\mathrm{KBr})$ disc method. $\mathrm{KBr}$ disc pellet was prepared by pressuring the powdery mixture of sample and $\mathrm{KBr}$ with a hydraulic pump at 7 tonne. A Perkin-Elmer FT-IR spectrophotometer was used.

\subsubsection{Field Emission Scanning Electron Microscope (FESEM)}

FESEM analysis of all samples was determined using JEOL 230, Japan. The samples were analysed on carbon tape without further coating and micrographs were taken at a magnification range of $10,000 \mathrm{X}$ to $75,000 \mathrm{X}$.

\subsubsection{UV-Visible spectroscopy (UV-Vis)}

The amount of immobilized tyrosinase was monitored by UV-Vis spectrometer based on Lowry assay. UV-Vis spectra of enzyme solution before and after immobilization treatment were recorded by Shimadzu spectrometer operating between $190 \mathrm{~nm}$ to $700 \mathrm{~nm}$ and compared to a prepared BSA standard solution.

\section{RESULTS \& DISCUSSION}

The chemical oxidation process opens the end cap of CNTs and created functional moieties at this active site 
along with other reactive defect sites along the walls. The methods of oxidation used in this study are capable of functionalizing MWCNTs but have different oxidation ability with acid mixture as strong oxidant while $\mathrm{KMnO}_{4}$ solution without acid catalyst is a mild oxidant. The acid mixture is highly oxidative with the ability to break or cut the tubes of MWCNTs depending on the technique used for the oxidation reaction and is regarded as a harsh method. Eventhough, the $\mathrm{KMnO}_{4}$ is a mild oxidant, it is strong enough to generate functional groups on MWCNTs with different amount of functional groups, depending upon the technique of oxidation reaction used. The functionalization of MWCNTs was studied by FT-IR spectra as shown in Figure 1.

The presence of hydroxyl groups is consistent with the broad peak observed in the range of 3000 to $3600 \mathrm{~cm}^{-1}$ and the presence of carboxyl groups at $1720 \mathrm{~cm}^{-1}$ for all samples. The slight shift of carboxyl peak from $1750 \mathrm{~cm}^{-1}$ to a lower wavelength of $1720 \mathrm{~cm}^{-1}$ is caused by conjugation effect due to the attachment to benzene ring of CNTs wall or at end tube.
The carboxyl peak also overlapped with another peak of $1650 \mathrm{~cm}^{-1}$ of hydrogen-bonded carbonyl stretching.his $\mathrm{H}$ bonded carbonyl stretching was also spotted by other researchers but at $1636 \mathrm{~cm}^{-1}$ and the occurrence of this peak is used to support the presence of carboxyl groups on CNTs [17]. During the reaction, manganese ion (Mn) oxidation state of +7 was reduced to +4 by forming manganese dioxide $\left(\mathrm{MnO}_{2}\right)$ compound. The leftover reduced manganese presence can be detected in FT-IR spectra of every sample at the fingerprint region of $539 \mathrm{~cm}^{-1}$. The formation of $\mathrm{MnO}_{2}$ can also be observed directly during reaction through changes in mixture color, from dark purple to dark brown. This observation is corroborated by previous research [18]. In order to verify the presence of manganese dioxide after treatment, a sample of commercial analytical grade manganese dioxide is analyzed by FT-IR. The result demonstrated a high intensity sharp peak at $539 \mathrm{~cm}^{-1}$ hence, confirming the presence of manganese dioxide leftover from the experiment. The FT-IR results of functionalization are supported by titration result as shown in Table 1 .

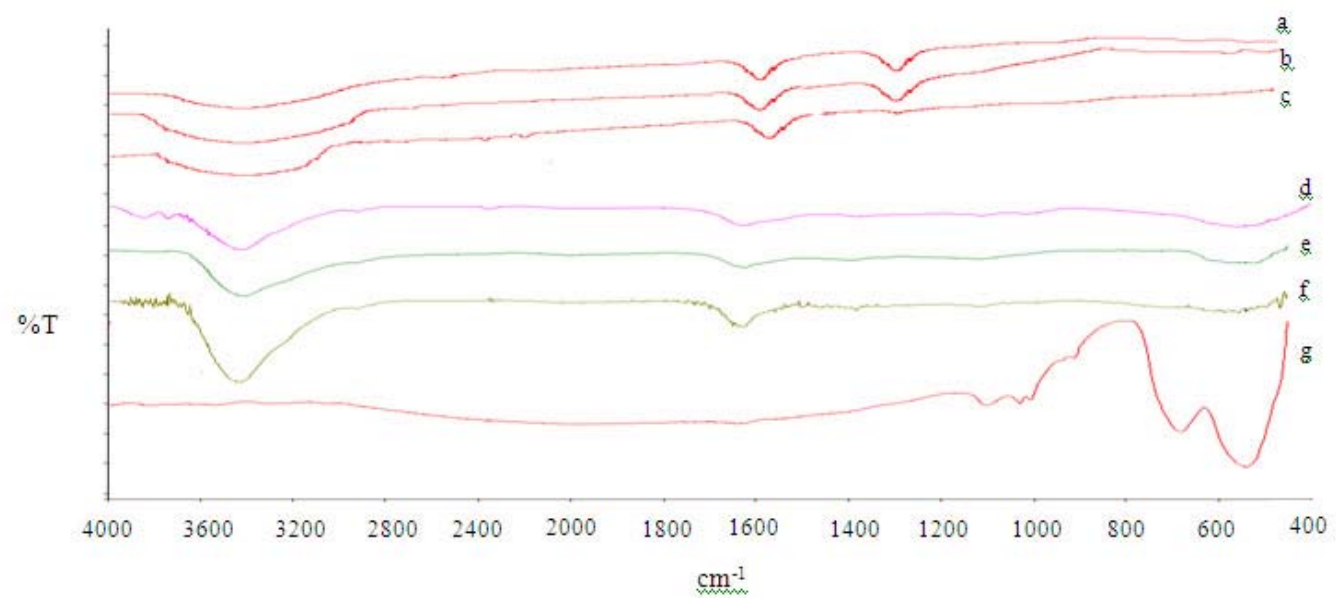

Figure 1: Spectra of FCNTs from top: (a) acid-reflux, (b) acid-sonic, (c)acid-stir, (d) $\mathrm{KMnO}_{4}-$ stir, (e) $\mathrm{KMnO}_{4}-\mathrm{reflux}$, (f) $\mathrm{KMnO}_{4}-$ sonic and (g) commercial $\mathrm{MnO}_{2}$.

Table 1: Titration results of FCNTs

\begin{tabular}{lll}
\hline Sample & $\begin{array}{l}\text {-COOH } \\
\text { concentration } \\
\text { (mmol/g) }\end{array}$ & $\begin{array}{l}-\mathrm{OH} \\
\text { concentration } \\
\text { (mmol/g) }\end{array}$ \\
\hline Acid-reflux & $8.5 \pm 0.29$ & $1.1 \pm 0.23$ \\
Acid-sonic & $9.2 \pm 0.27$ & $1.3 \pm 0.23$ \\
Acid-stir & $3.5 \pm 0.24$ & $1.4 \pm 0.22$ \\
$\mathrm{KMnO}_{4}$-reflux & $1.2 \pm 0.23$ & $2.0 \pm 0.24$ \\
$\mathrm{KMnO}_{4}$-sonic & $4.3 \pm 0.27$ & $2.8 \pm 0.25$ \\
$\mathrm{KMnO}_{4}$-stir & $2.5 \pm 0.24$ & $1.8 \pm 0.21$ \\
\hline $\mathrm{SD}(\mathrm{n}=3)$ & &
\end{tabular}

The morphology of pristine or untreated MWCNTs has smooth and structured walls as shown in Figure 2.
However, after the nanotubes were treated excessively with acid, the majority of the nanotubes' wall structure of smooth wall had change to groovy surface structure as seen in the acid-treated micrograph of CNTs. These groovy walls were actually formed by defect sites introduced via carboxylic group attachment to the side wall and resulted in swelling of the CNTs floss. The presence of impurities such as catalyst or support that can be observed in pristine CNTs micrograph as bright particles with bundles of nanotube is circled in Figure 2. The presence of impurities were not detected in the acid treated MWCNTs, which is probably due to the oxidation during reaction with acid. The most common catalyst used for CNTs production is mainly metal or metal oxide that can be dissolved and oxidized by acids and the result is as expected. Further washing with distilled 
water and acetone after reaction ensure that these impurities are completely eliminated. The structural changes of FCNTs treated by $\mathrm{KMnO}_{4}$ are quite drastic with the formation of manganese oxide layer enclosing the outer walls of the tube as shown in Figure 2 (d). Consequently, this increased the nanotubes mass almost twice of its original mass. This increased in mass of tubes affected the dispersion stability of the FCNTs as shown in Table 2.
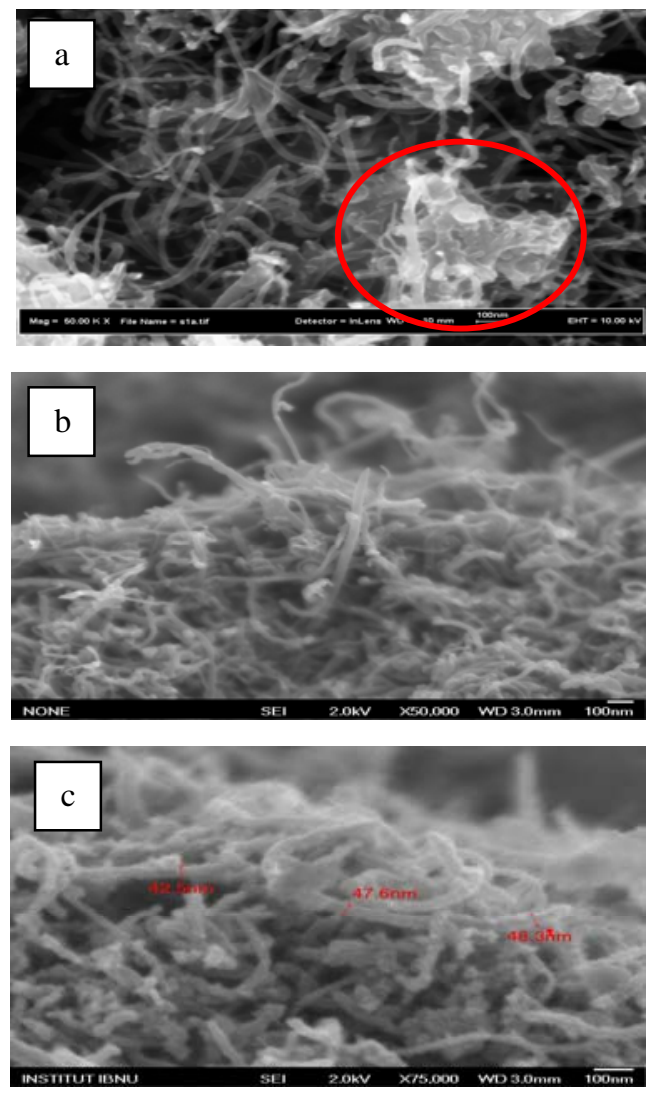

Figure 2: FESEM micrograph of (a) pristine MWCNTs, (b) acidtreated MWCNTs, (c) $\mathrm{KMnO}_{4}$-treated MWCNTs at magnification of $50 \mathrm{~K}$.

Table 2: Stability of FCNTs suspension in aqueous

\begin{tabular}{lc}
\hline Sample & $\begin{array}{c}\text { Stability of } \\
\text { suspension } \\
\text { (hours) }\end{array}$ \\
\hline Acid-reflux & 72.0 \\
Acid-sonic & 72.0 \\
Acid-stir & 72.0 \\
$\mathrm{KMnO}_{4}$ & 2.5 \\
reflux & 60 \\
$\mathrm{KMnO}_{4}$-sonic & 1.5 \\
$\mathrm{KMnO}_{4}$-stir & \\
\hline
\end{tabular}

The stability of FCNTs suspension is tabulated in Table 2. The oxidative process with both acid mixture and $\mathrm{KMnO}_{4}$ generates polar carbonyl and hydroxyl groups on the FCNTs. Thus, it is expected that FCNTs suspension is better dispersed as compared to the pristine MWCNTs especially in polar solvent such as deionized water. All samples of FCNTs treated by acid mixture have high suspension stability whereas the pristine MWCNTs sample settled in less than 2 minutes. In contrast to the acid-treated samples, $\mathrm{KMnO}_{4}$ - samples have different stability with sample treated via sonication showed s relatively a stable suspension. During sonication, the tubes of FCNTs were broken into shorter tubes and created larger amount of functional moieties. Even though, the mass of the FCNTs after sonication with $\mathrm{KMnO}_{4}$ is increased, the ratio of functionalized length to weight is high and enables the tubes to disperse well and remained stable for a longer duration as compared to other two techniques. The amount of functional moieties present and the dispersion stability affect the immobilization of Tyrosinase. The highest immobilization occurred on acid treated by sonication technique FCNTs as shown in Figure 3. The leaching study of the MWCNTs sample shows a gradual increased of enzyme leached out. The FCNTs sample leaching declined and ended shows that the enzyme has good attachment to the CNTs. The presence of high carbonyl groups that probably bind with amide groups in the enzyme create a better linkage between enzyme and FCNTs. Thus, it is harder to leach out.
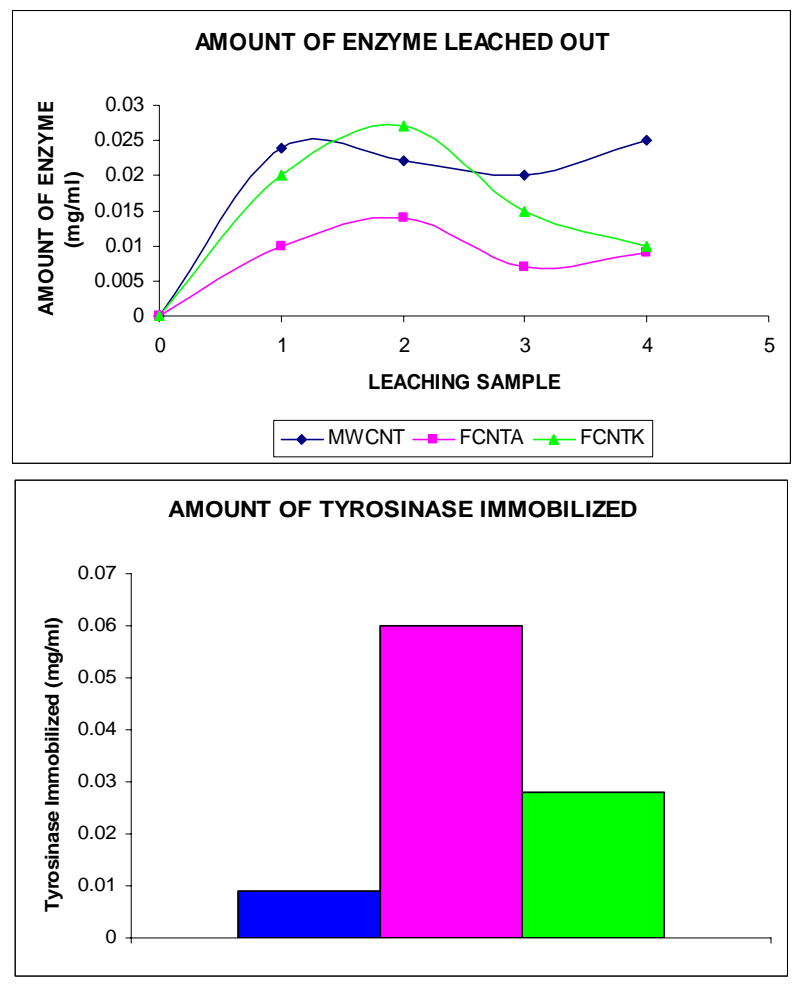

Figure 3: Amount of enzyme leached out and amount of enzyme immobilized on the CNTs 


\section{CONCLUSION}

In conclusion, oxidants have significant effect on the surface modification of MWCNTs due to their different ability. Strong oxidants such as sulfuric acid and nitric acid mixture generates higher amount of functional moieties on the FCNTs. Technique for oxidative reaction also contributes to the oxidation process where sonication provide high pressure, refluxing provides energy, and stirring provide high contact between reaction. Among the three techniques studied, sonication is the best technique for functionalization via oxidative reaction. By sonication at 6 hours, a mild oxidant such as $\mathrm{KMnO}_{4}$ can also create relatively high amount of carboxyl and hydroxyl groups. The dispersion of acid-treated FCNTs is high and stable for a longer period meanwhile the increased in weight of
$\mathrm{KMnO}_{4}$ - treated FCNTs showed unstable suspension except for the sonicated sample. The amount of functional moieties present and dispersion stability affect the immobilization of Tyrosinase with the highest immobilization on acid FCNTs treated by sonication technique.

\section{ACKNOWLEDGEMENT}

This work is funded by the Ministry of Higher Education (MOHE), Malaysia under the Fundamental Research Grant Scheme (Vot Number 78318).

\section{REFERENCES}

[1] de Heer, W. A.; Chatelain, A.; Ugarte, D. Science 1995, 270, 1179.

[2] Choi, W. B.; Jin, Y. W.; Kim, H. Y. et al. Appl. Phys. Lett. 2001,78, 1547

[3] Wang, Q. H.; Setlur, A. A.; Lauerhaas, J. M.; Dai, J. Y.; Seeling, E. W.; Chang, R. P. H., Appl. Phys. Lett. $1998,72,2912$.

[4] Saito, S. Science 1997, 278, 77

[5] Tans, S. J.; Verscheueren, A. R. M.; Dekker: C. Nature 1998, 393,49.

[6] Lefebvre, J.; Antonov, R. D.; Radosavljevic, M. et al. Carbon 2000,38, 1745.

[7] Haggenmueller, R.; Gommans, H. H.; Rinzler, A. G. et al. Chem. Phys. Lett. 2000, 330, 219.

[8] Jin, Z.; Pramoda, K. P.; Xu, G.; Goh, S. H. Chem. Phys. Lett. 2001,337, 43.

[9] Ajayan, P. M.; Schadler, L. S.; Giannaris, C.; Rubio, A. AdV. Mater.2000, 12750.

[10] Wong, S. S.; Harper, J. D.; Lansbury Jr., P. T. et al. J. Am. Chem.Soc. 1998, 120,603.

[11] Ausman, K. D.; Piner, R.; Lourie, O.; and Ruoff, R. S.; Korobov,M., J. Phys. Chem. B 2000, 104(38), 8911.

[12] Sheeney-Haj-Ichia, L.; Basnar, B.; Willner, I. Angew. Chem. 2005,117, 80-85.

[13] Luong, J. H. T.; Hrapovic, S.; Liu, Y.; Yang, D. Q.; Sacher, E.;Wang, D.; Kingston, C. T.; Enright, G. D. J. Phys. Chem. B 2005, 109,1400-1407.

[14] Gomez J.M., Romero M.D., and Fernandez T.M. (2005), Catalysis Letters. 101, 275-278

[15] Durán, N., Rosa, M.A., D’Annibale, A., Gianfreda, L., (2002), Enz. Microb. Tech. 31,907-931

[16] Chen, R.J., Zhang, Y., Wang, D., Dai, H., (2001), J. Am. Chem. Soc. 123, 3838-3839

[17] A. K. Jain, MPharm, V. Dubey, MPharm, N. Kumar Mehra, MPharm, N. Lodhi, MPharm, M. N., Mpharm, Nanomedicine, (2009).

[18] Chen Z., Thiel W., Hirsh A. (2003), Phys. Chem.. 4, 93-97

[19] Wang J., and Lin Y., (2008), Trends Anal. Chem. 05.009 